\title{
Study of Functional Verification to Abiotic Stress through Antioxidant Gene Transformation of Pyropia yezoensis (Bangiales, Rhodophyta) APX and MnSOD in Chlamydomonas
}

\author{
Hak-Jyung Lee ${ }^{1}$, Ho yeon Yang ${ }^{2}$, and Jong-il Choi ${ }^{1 *}$ \\ ${ }^{1}$ Department of Biotechnology and Bioengineering, Interdisciplinary Program for Bioenergy and Biomaterials, Chonnam National University, \\ Gwangju 61186, Republic of Korea \\ ${ }^{2}$ Microbial Institute for Fermentation Industry, Sunchang 56048, Republic of Korea
}

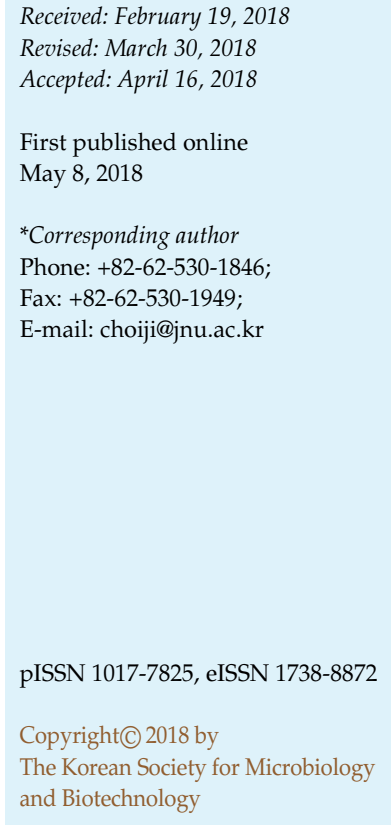

Seaweeds produce antioxidants to counteract environmental stresses, and these antioxidant genes are regarded as important defense strategies for marine algae. In this study, the expression of Pyropia yezoensis (Bangiales, Rhodophyta) ascorbate peroxidase (PyAPX) and manganese-superoxide dismutase $(P y M n S O D)$ was examined by qRT-PCR in $P$. yezoensis blades under abiotic stress conditions. Furthermore, the functional relevance of these genes was explored by overexpressing them in Chlamydomonas. A comparison of the different expression levels of $P y A P X$ and $P y M n S O D$ after exposure to each stress revealed that both genes were induced by high salt and UVB exposure, being increased approximately 3-fold after $12 \mathrm{~h}$. The expression of the PyAPX and PyMnSOD genes also increased following exposure to $\mathrm{H}_{2} \mathrm{O}_{2}$. When these two genes were overexpressed in Chlamydomonas, the cells had a higher growth rate than control cells under conditions of hydrogen peroxide-induced oxidative stress, increased salinity, and UV exposure. These data suggest that Chlamydomonas is a suitable model for studying the function of stress genes, and that PyAPX and PyMnSOD genes are involved in the adaptation and defense against stresses that alter metabolism.

Keywords: Pyropia yezoensis, ascorbate peroxidase, MnSOD, Chlamydomonas reinhardtii, transformation, abiotic stress tolerance

\section{Introduction}

Red algae (Rhodophyta), including the genus Pyropia, are the oldest lineage of photosynthetic eukaryotes [1]. Pyropia grows in the intertidal zone, an environment that undergoes dynamic changes, and so accordingly Pyropia is exposed to wide variations in temperature, osmotic strength, and light [2]. These environmental stresses result in the accumulation of reactive oxygen species (ROS), including hydrogen peroxide $\left(\mathrm{H}_{2} \mathrm{O}_{2}\right)$, singlet oxygen $\left(\mathrm{O}_{2}^{-}\right)$, and hydroxyl radicals $\left(\mathrm{OH}^{-}\right)$[3]. The ROS generated through these environmental stresses inhibit the growth of algae by interfering with integral metabolic processes.

In both algae and higher plants, antioxidant systems, such as the enzymes ascorbate peroxidase (APX) and superoxide dismutase (SOD), are known to be the principal protective mechanisms against oxidative stress [3-6]. In order to scavenge ROS, APX catalyzes the conversion of $\mathrm{H}_{2} \mathrm{O}_{2}$ to $\mathrm{H}_{2} \mathrm{O}$ and $\mathrm{O}_{2}$ within the chloroplast and cytosol of photosynthetic cells using ascorbate as the specific electron donor [7, 8]. The SOD enzyme family converts the superoxide radicals to $\mathrm{H}_{2} \mathrm{O}_{2}$ and oxygen. The SOD family members are classified according to the metal species that is present in their redox active centers. Generally, SODs are divided into three classes: MnSOD is found in the cytosol and the thylakoid membrane, Fe- and NiSODs are found in the cytosol, and $\mathrm{Cu} / \mathrm{ZnSODs}$ are found in the periplasm [9, 10]. APX and SODs are therefore important enzymes in protecting against oxidative damage.

Studies examining the relationship between environmental 
stress resistance and increased antioxidants have been conducted in higher plants [11-14] as well as in algae [1521]. In addition, the mechanisms of action of antioxidant enzymes have been elucidated following treatment with various abiotic stresses in Pyropia [22-24]. The search for stress-related genes is crucial to elucidating adaptive mechanisms under the stresses of plants or algae.

The unicellular green alga Chlamydomonas reinhardtii has been used extensively as a model system for understanding numerous biological processes in eukaryotes at the molecular level [25-30]. Moreover, the full sequences of the Chlamydomonas genome, its plasmids, and its mitochondrial genome are available and the organism is amenable to genetic manipulation by transformation [31-33].

Recently, studies using transformation have been conducted in Chlamydomonas to characterize the function of the heat shock proteins (HSPs) from Porphyra seriata and Pyropia tenera, [34-36]. Similarly, the role of cyclophilins in protein folding, symbiosis, and plant responses to abiotic stress have also been examined following their transformation into Chlamydomonas [37]. Chlamydomonas species are photoautotrophs that have advantages over yeast for elucidating the functional relevance of genes that respond to plant and alga stress [38]. However, little research has been performed aimed at characterizing the biological and molecular mechanisms of stress responses following the transformation of Pyropia yezoensis antioxidant genes into Chlamydomonas.

In this study, the expression pattern of antioxidant genes of P.yezoensis (PyAPX and PyMnSOD) was analyzed following abiotic stress treatment. In addition, we examined the functional role of $P y A P X$ and PyMnSOD following their expression in Chlamydomonas.

\section{Materials and Methods}

\section{Sample Culture and Experimental Conditions}

Gametophytes of $P$. yezoensis were provided by the Seaweed Research Center at Mokpo, Korea. Blades were cultured in modified Grund medium under light intensity of $80 \mu \mathrm{mol}$ photons $\cdot \mathrm{m}^{-2} \cdot \mathrm{s}^{-1}$ and $10 \mathrm{~h}$ light $/ 14 \mathrm{~h}$ dark cycle at $12^{\circ} \mathrm{C}$ in a growth chamber. These cultures were continuously aerated with filter-sterilized air, and the medium was renewed weekly. Subsequent experiments were performed using the gametophyte blade cultured at 1 month.

$\mathrm{H}_{2} \mathrm{O}_{2}$ and $\mathrm{NaCl}$ were used to examine the effect of stress on gene expression using a slight modification of the method described by Jin et al. [36]. P. yezoensis blades were placed in a 200-ml flask and treated with $1 \mathrm{mM} \mathrm{H}_{2} \mathrm{O}_{2}$ or $100 \mathrm{mM} \mathrm{NaCl}$, and each treated flask was maintained under stationary culture conditions at $12^{\circ} \mathrm{C}$ for 0 to $12 \mathrm{~h}$. To induce UV stress, healthy blades were selected and transferred to a $200-\mathrm{ml}$ flask and irradiated with UVB (285 nm; $0.26 \mathrm{~W} / \mathrm{m}^{2}$ ) at $12^{\circ} \mathrm{C}$ for 6 or $12 \mathrm{~h}$. All samples were extracted immediately before or after treatment with the abiotic stresses.

The GeneArt Chlamydomonas TOPO Engineering Kit contains the components of the C. reinhardtii c137 strain (Invitrogen, USA). Cells were grown in modified Tris-acetate-phosphate (TAP)

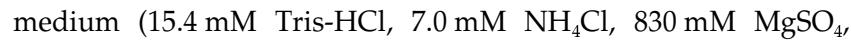
$337 \mathrm{mM} \mathrm{CaCl}_{2}, 490 \mathrm{mM} \mathrm{K}_{2} \mathrm{HPO}_{4}, 400 \mathrm{mM} \mathrm{KH} \mathrm{PO}_{4}, 17.4 \mathrm{mM}$ acetic acid, and Hutner's trace elements, pH 7.0). Chlamydomonas cells were cultured at $25^{\circ} \mathrm{C}$ in liquid TAP medium, with shaking at $120 \mathrm{rpm}$ under a continuous cool fluorescent light $\left(50 \mu \mathrm{mol} \cdot \mathrm{m}^{-2} \cdot \mathrm{s}^{-1}\right)$.

\section{Gene Expression Analysis}

Total RNA extraction from leafy gametophyte thalli was performed using an RNeasy Plant Mini kit (Qiagen, USA). Firststrand cDNA was constructed from $2 \mu \mathrm{g}$ of total RNA via reverse transcription in a $20 \mu \mathrm{l}$ reaction volume using an oligo(dT)17 primer, and Superscript II reverse transcriptase, in accordance with the manufacturer's instructions (BRL Life Technologies, USA). The reaction was carried out for $60 \mathrm{~min}$ at $52^{\circ} \mathrm{C}$, followed by $5 \mathrm{~min}$ of heating at $70^{\circ} \mathrm{C}$. The first-strand cDNA reaction mixture was diluted 5 -fold, and then $2 \mu$ of the diluted cDNA was added to a $50-\mu 1$ PCR mixture containing $5 \mu$ l of $10 \times$ PCR buffer (200 mM Tris- $\mathrm{HCl}, \mathrm{pH} 8.4,500 \mathrm{mM} \mathrm{KCl}), 1 \mu \mathrm{l}$ of $10 \mathrm{mM}$ dNTPs, $1 \mu \mathrm{l}$ of each gene-specific primer $(10 \mu \mathrm{M})$, and 2.5 units of ExTaq DNA polymerase (Takara, Japan). PCRs were conducted for 35 cycles, each consisting of $30 \mathrm{sec}$ at $95^{\circ} \mathrm{C}, 30 \mathrm{sec}$ at $60-64^{\circ} \mathrm{C}$, and $90 \mathrm{sec}$ at $72^{\circ} \mathrm{C}$, and $7 \mathrm{~min}$ of termination at $72^{\circ} \mathrm{C}$. The APX and MnSOD gene-specific primers from NCBI were as follows: $P y A P X$ (Accession No. AY282755.1); PyMnSOD (Accession No. DQ146477.2); Py18S (sAccession No. D79976.2); and transgenic primers were prepared and used in the experiment (Table 1). The PCR products were separated by electrophoresis on $1 \%$ agarose gels.

All qRT-PCRs were performed using the following amplification program: $50^{\circ} \mathrm{C}$ for $2 \mathrm{~min}, 95^{\circ} \mathrm{C}$ for $10 \mathrm{~min}$, and 40 cycles at $95^{\circ} \mathrm{C}$, $58^{\circ} \mathrm{C}$, and $95^{\circ} \mathrm{C}$ for $15 \mathrm{sec}$. All real-time PCRs were performed under the following conditions: $30 \mathrm{sec}$ at $95^{\circ} \mathrm{C}$, followed by 40 cycles of $5 \mathrm{sec}$ at $95^{\circ} \mathrm{C}$, and $30 \mathrm{sec}$ at $60^{\circ} \mathrm{C}$. The specificity of the PCR products was confirmed by analyzing their dissociation curves at the end of each reaction $\left(15 \mathrm{sec}\right.$ at $95^{\circ} \mathrm{C}, 1 \mathrm{~min}$ at $60^{\circ} \mathrm{C}$, and $15 \mathrm{sec}$ at $\left.95^{\circ} \mathrm{C}\right)$. The reaction mixture $(20 \mu \mathrm{l})$ contained $10 \mu \mathrm{l}$ of SYBR Premix Ex Taq GC (TaKaRa Bio, Japan), $0.8 \mu$ l of each forward and reverse primer $(5 \mu \mathrm{M}), 0.4 \mu \mathrm{l}$ of ROX Reference Dye, and $4 \mu \mathrm{l}$ of cDNA template (50-fold dilution). The actin gene was used as an internal control to standardize the amount of mRNA in each reaction. The levels of the Py18S mRNA were calculated on the basis of a standard curve. All experiments were conducted in triplicate. The relative expression level was calculated as a ratio to the transcription level at $0 \mathrm{~h}$ after stress treatment.

Genomic DNA was extracted using a PureLink Genomic DNA Mini Kit (Invitrogen, USA) using $100 \mathrm{ml}$ of cultured Chlamydomonas. The extracted genomic DNA was used to confirm the insertion of PyAPX and PyMnSOD into the Chlamydomonas genome using 
Table 1. Primers used in the present study.

\begin{tabular}{|c|c|c|}
\hline Primer name & $\left(5^{\prime}-3^{\prime}\right)$ Nucleotide sequence & Target \\
\hline PyAPX qRT-PCR F & ATCAGCTACGCGGACCTCTA & qRT-PCR \\
\hline PyAPX qRT-PCR R & AAGCCCATCCGGTAAAAGAT & \\
\hline$P y M n S O D$ qRT-PCR F & GCTGTTCATCAGCAGCACTC & \\
\hline$P y M n S O D$ qRT-PCR R & ACGTCAAAGTCGACGGTCTT & \\
\hline 18S rRNA F & CGACCGTTTACTGTGAAG & \\
\hline 18S rRNA R & GACAATGAAATACGAATGCC & \\
\hline TOPO_PyAPX F & CACCGTGTCTGACCTGGAGAAGGCGGTCCGCGCC & Transformation \\
\hline TOPO_PyAPX R & TCACGCCCAAACCGCGCCCAACTCACTCA & \\
\hline TOPO_PyMnSOD F & CACCGCGTTTGCTCTGCCCCCCCTGCCCTATGCG & \\
\hline TOPO_PyMnSOD R & TTACACCAGCGGCGTGTCAAAGGCAGGCAG & \\
\hline CrActin $\mathrm{F}$ & TGTGCATACGTGGATAGCTTG & \\
\hline CrActin R & ATGACCCGCTCCTCATATCTT & \\
\hline
\end{tabular}

specific PCR primers. Chlamydomonas actin (Accession No. D50838.1) was used as an internal control gene.

\section{Plasmid Construction and Chlamydomonas Transformation}

The PCR products were subcloned into the pChlamy_1/DTOPO vector (Invitrogen, USA) using the GeneArt Chlamydomonas TOPO Engineering Kit according to the manufacturer's protocol. The pChlamy_1/D-TOPO vector harbors regulatory sequences with the psaD promoter and a terminator driven by the Chlamydomonas c137 genome for transgene expression. Additionally, it possesses a hygromycin resistance gene (aph7) under the control of the tubB2 promoter and the Hsp70A-RbcS2 terminator for the selection of transformants. The open reading frames of the PyAPX and $P y M n S O D$ genes were amplified by PCR and subcloned into the pChlamy_1/D-TOPO vector using the KpnI and BglII sites. To transform the DNA into Chlamydomonas c137, the PyAPX and $P y M n S O D$ plasmids were linearized with ScaI, and the cells were electroporated using the Gene Pulser Xcell (Bio-Rad, USA). The electroporation parameters were as follows: $600 \mathrm{~V}, 50 \mu \mathrm{F}$. After 2 weeks of growth on 24-well plates, the transformed colonies were selected on TAP agar medium containing $10 \mu \mathrm{g} / \mathrm{ml}$ hygromycin (Invitrogen, USA).

\section{Abiotic Stress and Irradiation Tolerance in Transformed Chlamydomonas}

Transformed Chlamydomonas cells were grown in TAP medium containing hygromycin at $25^{\circ} \mathrm{C}$ under a $14 \mathrm{~h}$ light $/ 10 \mathrm{~h}$ dark cycle. To investigate oxidative and osmotic tolerances, agar plates supplemented with $0,2.5,5,7$, and $10 \mathrm{mM} \mathrm{H}_{2} \mathrm{O}_{2}$ or $0,10,25,50$, and $100 \mathrm{mM} \mathrm{NaCl}$ were prepared. We then diluted $2-4 \times 10^{6}$ of the initial cell concentration with fresh medium to reach a final concentration of $10^{1}-10^{5}$. Ten microliters of the diluted cells was inoculated onto the agar plates and cultured for 1 week. C. reinhardtii c137 and cells transformed with the pChlamy_1/D-TOPO vector were used as controls.
In order to measure the UV resistance of the transformed Chlamydomonas, cells were diluted to $10^{1}-10^{5}$ in fresh medium, and $10 \mu \mathrm{l}$ of the diluted cell suspension was inoculated onto agar plates, after which they were exposed to UV doses of 500, 1,000, 1,500, and 2,000 J (Ultraviolet Crosslinker CL-1000L; LLC, USA). The survival rate was then measured after transfer of the cells to a $25^{\circ} \mathrm{C}$ growth chamber and culture for 1 week with a $14 \mathrm{~h}$ light $/ 10 \mathrm{~h}$ dark photocycle.

\section{Results}

\section{Expression of Antioxidant Genes in Response to Abiotic} Stresses

We synthesized PyAPX and PyMnSOD gene-specific primers (Table 1) and analyzed the expression of these antioxidant genes after exposure of $P$. yezoensis blades to abiotic stress. As shown in Fig. 1A, the expression of these two antioxidant genes increased following exposure to oxidative stress. We found that within $3 \mathrm{~h}$ of $\mathrm{H}_{2} \mathrm{O}_{2}$ treatment, the expression levels of $P y A P X$ were significantly increased, whereas the expression levels of $P y M n S O D$ were only slightly increased. However, after $6 \mathrm{~h}$ of treatment, the expression of $P y M n S O D$ had increased to levels similar to those seen for PyAPX; however the expression levels of both genes declined by $12 \mathrm{~h}$.

Following $\mathrm{NaCl}$ treatment, the expression of these two antioxidant genes showed a similar pattern to that seen for $\mathrm{H}_{2} \mathrm{O}_{2}$ treatment. Both the PyAPX and PyMnSOD genes showed a gradual increase in their expression following $\mathrm{NaCl}$ treatment up to $3 \mathrm{~h}$, with $P y M n S O D$ expression being maintained at this level for up to $12 \mathrm{~h}$, while the levels of PyAPX declined slightly (Fig. 1B).

Fig. 1C shows that the expression levels of the PyAPX 

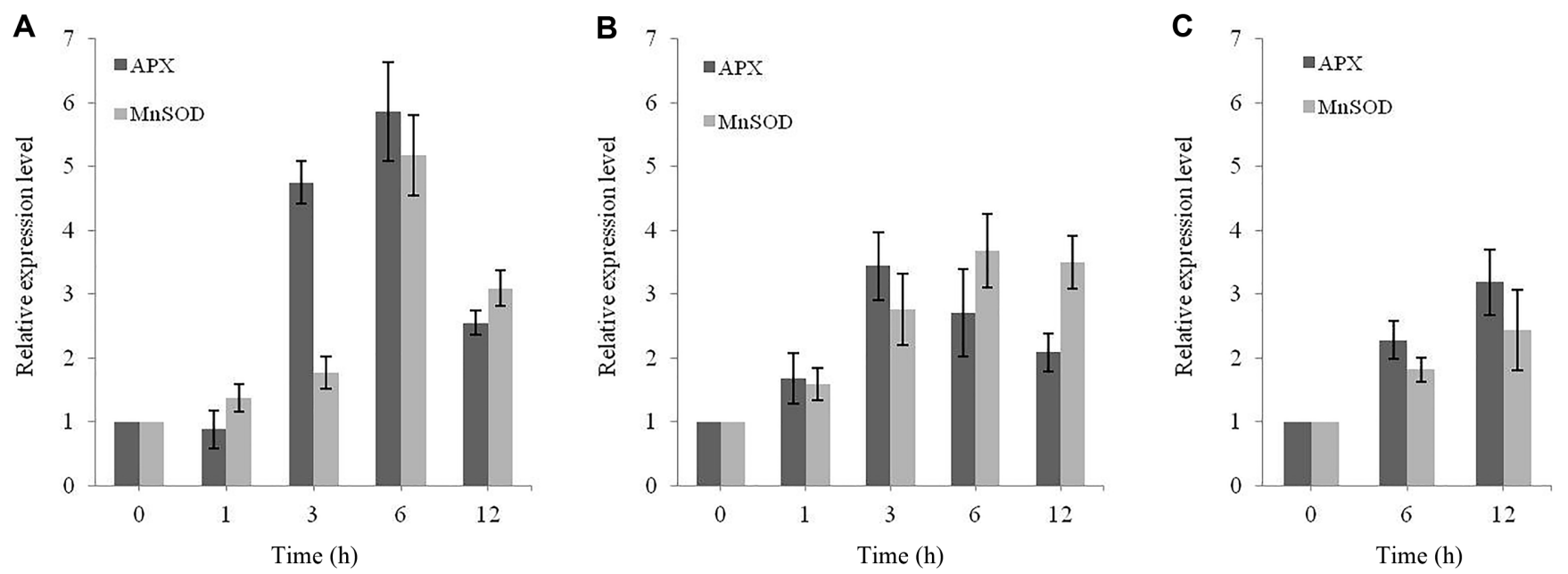

Fig. 1. Relative expression levels of $P y A P X$ and $P y M n S O D$ under abiotic stresses in $P$. yezoensis.

Gametophyte blades were harvested at 0,1,3,6, and $12 \mathrm{~h}$ to determine the transcript levels of PyAPX and PyMnSOD following exposure to either $\mathrm{H}_{2} \mathrm{O}_{2}$ and increased salinity. (A) Relative expression levels of $P y A P X$ and $P y M n S O D$ following $\mathrm{H}_{2} \mathrm{O}_{2}$ stress. (B) Relative expression levels of $P y A P X$ and $P y M n S O D$ following exposure to increased salinity. (C) Relative expression levels of PyAPX and PyMnSOD following exposure to UVB. Py18S RNA was used as the internal control gene. Bars represent the mean \pm standard deviation.

and $P y M n S O D$ genes were elevated following UVB exposure. The expression of both genes increased immediately following exposure to UVB stress, with an approximately 2-fold increase in expression occurring at $6 \mathrm{~h}$. The levels of $P y A P X$ and $P y M n S O D$ expression further increased to approximately 3 -fold after $12 \mathrm{~h}$ of UVB exposure.

This consumption by antioxidant genes could presumably minimize oxidative damage of the cells by removing ROS when exposed to stress conditions.

\section{Oxidative and Osmotic Tolerance of Transformed Chlamydomonas}

Chlamydomonas transformed with vectors encoding PyAPX and PyMnSOD were selected on a hygromycincontaining medium, and the successful introduction of the PyAPX and PyMnSOD genes was confirmed by RT-PCR and qRT-PCR (Fig. 2). We isolated one hygromycinresistant Chlamydomonas clone following transformation with a plasmid encoding the PYAPX gene, and confirmed the successful expression of the PyAPX gene by RT-PCR (Figs. 2A and 2B). In the case of $P y M n S O D$, we obtained four independent hygromycin-resistant clones. The clone $P y M n S O D \_2$ showed the highest level of PyMnSOD expression compared with the other three transformed lines (Figs. 2C and 2D). For this reason, we elected to study the effect of abiotic stress on this PyMnSOD_2 transformed Chlamydomonas line. Fig. 2E shows PCR confirmation of the successful insertion of the PyAPX and PyMnSOD genes into the Chlamydomonas genome.

To assess salt tolerance, the Chlamydomonas strains expressing PyAPX or $\mathrm{PyMnSOD}$ were cultured on agar plates treated with different concentrations of $\mathrm{NaCl}$, with Chlamydomonas strain c137 and vector-only transformed Chlamydomonas as controls. All Chlamydomonas cells were observed to grow at similar levels on agar plates at 10 and $25 \mathrm{mM} \mathrm{NaCl}$. However, when cells were grown on plates at $50 \mathrm{mM} \mathrm{NaCl}$, the Chlamydomonas expressing either PyAPX or $P y M n S O D$ exhibited better growth than Chlamydomonas c137 or Chlamydomonas transfected with an empty vector (Fig. 3A).

Growth was also compared on plates supplemented with 1-10 $\mathrm{mM} \mathrm{H}_{2} \mathrm{O}_{2}$ to assess tolerance to oxidative stress. All cells exhibited similar growth at 2.5 and $5 \mathrm{mM} \mathrm{H}_{2} \mathrm{O}_{2}$, but interestingly, at a concentration of $7.5 \mathrm{mM} \mathrm{H}_{2} \mathrm{O}_{2}$, only the transformed Chlamydomonas cells survived. Based on these data, the transformed Chlamydomonas cells proved to be more resistant to salt or oxidative stress than the control Chlamydomonas cells (Fig. 3B). In order to measure the UV resistance of the transformed Chlamydomonas following UV treatment, the cells were inoculated onto agar plates and exposed to various UV doses. The control and transformed Chlamydomonas cells grew at similar rates after exposure to UV doses of 0 and $500 \mathrm{~J} /$ plate, but at higher UV intensities $(1,000$ and 1,500 J), the transformed Chlamydomonas showed greater survival than the control cells (Fig. 3C). However, neither the control nor the transformed Chlamydomonas cell 

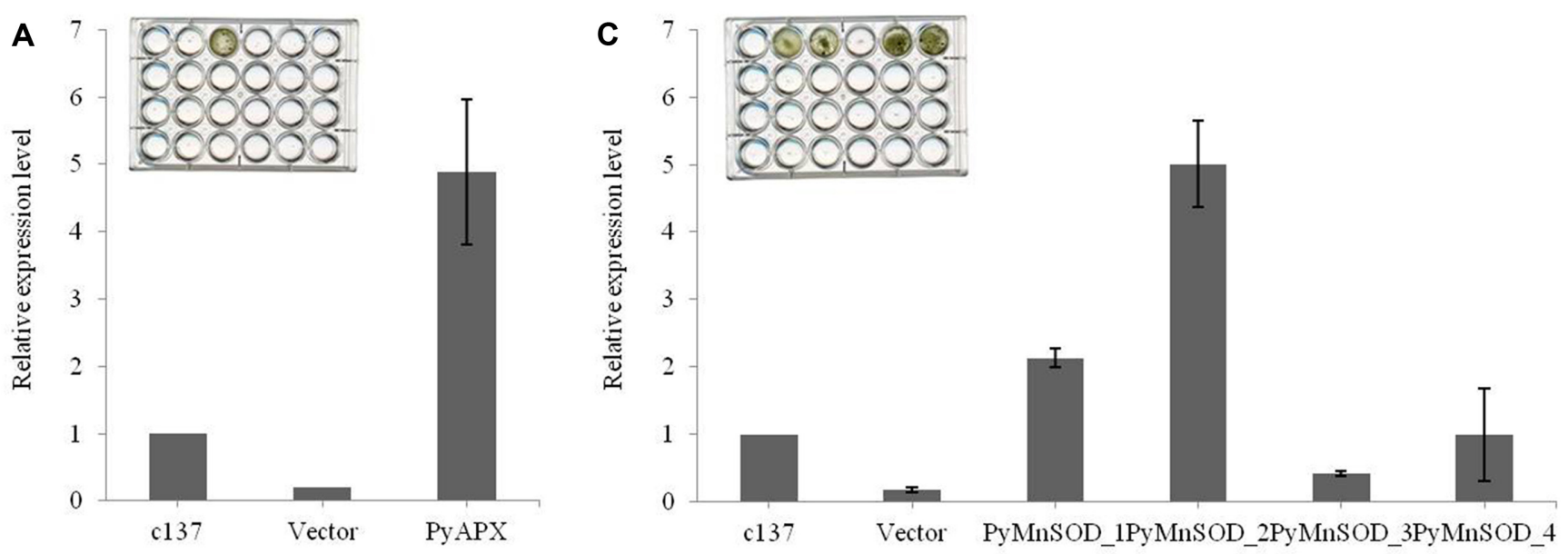

B

c137 Vector T1

D
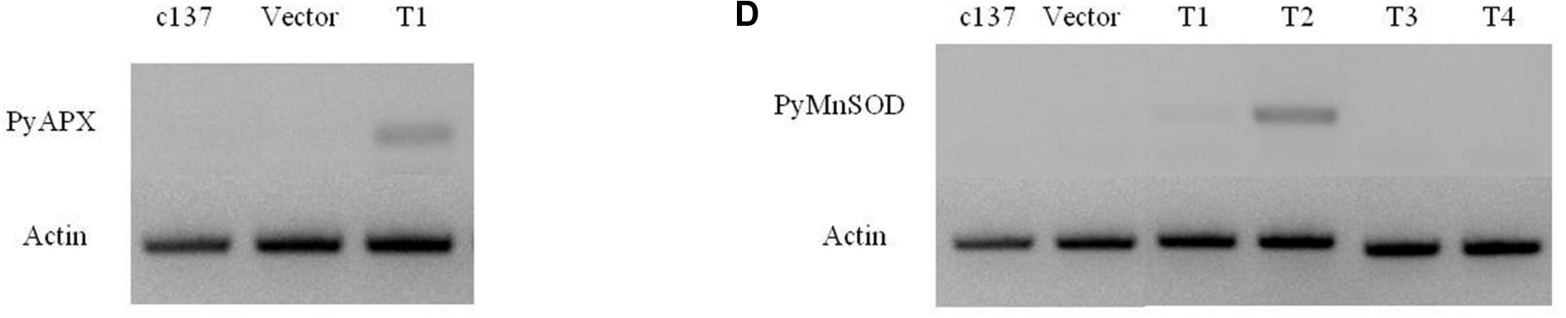

$\mathbf{E}$

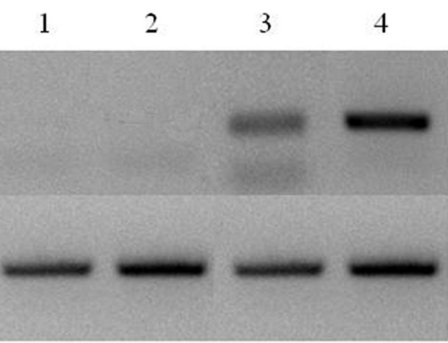

Fig. 2. Verification of the introduction and expression of the PyAPX and PyMnSOD genes in Chlamydomonas.

cDNA was extracted from the indicated transformed Chlamydomonas cells and amplified with either PyAPX or PyMnSOD specific primers, as appropriate. (A, B) Confirmation of the introduction of the PyAPX gene in one clone by RT-PCR. (C, D) Confirmation of the introduction of the $P y M n S O D$ gene in four clones by RT-PCR. (E) PCR confirmation of gene introduction into transformed Chlamydomonas cells, using genomic DNA. 1. Chlamydomonas c137; 2. Confirmation of empty TOPO_vector introduced into Chlamydomonas; 3. Confirmation of PyAPX gene introduced into Chlamydomonas; 4 . Confirmation of $P y M n S O D$ gene introduced into Chlamydomonas.

lines were detected on the culture plates after exposure to 2,000 J of UV radiation.

These results suggest that the PyAPX and PyMnSOD genes contribute to abiotic stress tolerance in Chlamydomonas.

\section{Discussion}

Pyropia species inhabiting the intertidal zone are inevitably exposed to high temperatures, UV radiation, high salinity, and oxidative stress. These stressors can inhibit growth, photosynthesis, and pigment synthesis, and cause DNA damage. They also cause the accumulation of intracellular ROS, leading to mitochondrial changes and damage to chloroplasts and phycobilisomes [39-42]. In the case of macroalgae, they respond to stress by increasing the expression of antioxidant defense enzymes such as the ROS scavenging enzymes APX and SOD, and these enzymes have an important role in effectively eliminating the stressinduced ROS [43-45]. In Ulva fasciata, antioxidant genes and enzymes have been found to be overexpressed under high salt stress conditions, suggesting that they are important in stress response [46]. In addition, it has been 
A

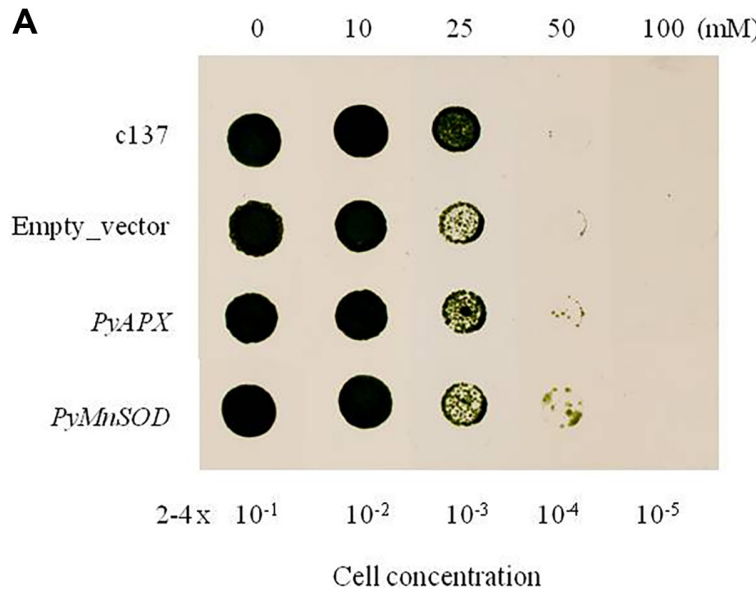

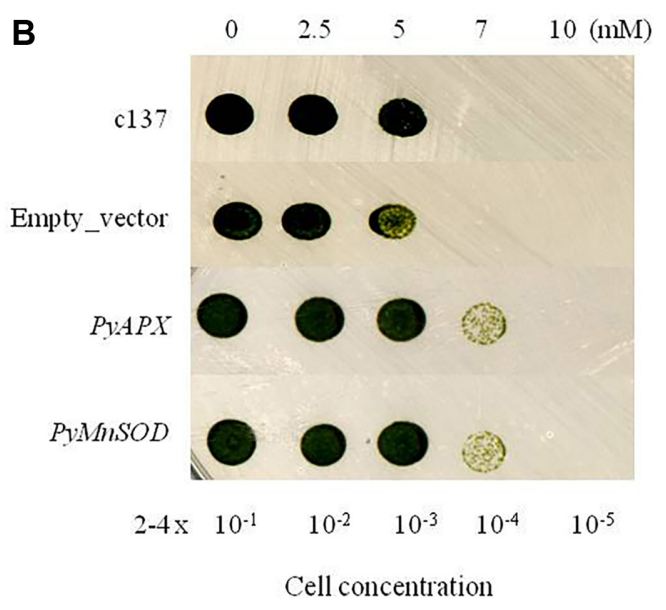

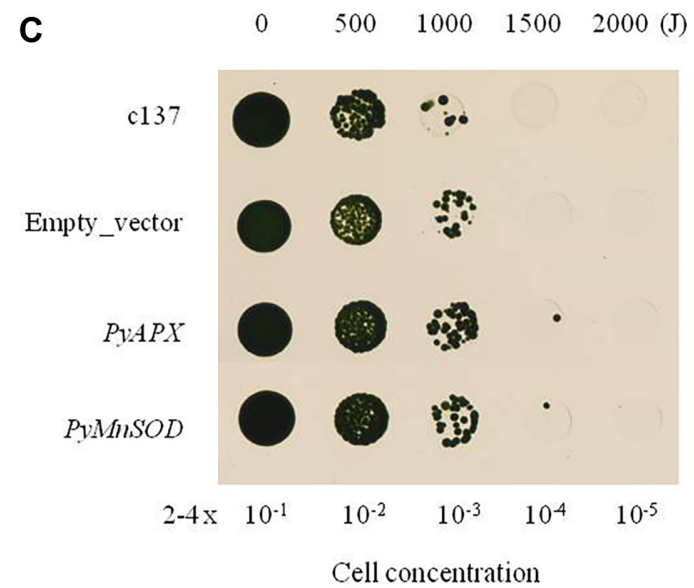

Fig. 3. Survival and growth pattern of transformed Chlamydomonas cells under $\mathrm{H}_{2} \mathrm{O}_{2}$ or salt stress conditions.

(A) Cells were inoculated on agar plates prepared by supplementation with $0,10,25$, 50 , or $100 \mathrm{mM} \mathrm{NaCl}$, and cultured for 1 week. (B) Cells were inoculated on agar plates prepared by supplementation with $0,2.5,5,7$, or $10 \mathrm{mM} \mathrm{H}_{2} \mathrm{O}_{2}$, and cultured for 1 week. (C) Survival and growth pattern of transformed Chlamydomonas cells under UV stress conditions. Cells were inoculated on the agar plate and irradiated with UV at doses of 0, 500, 1,000, 1,500, or 2,000 J UVB, followed by incubation for 1 week. Chlamydomonas strain c137 and empty TOPO_vector-transformed cells were used as controls.

reported that treatment of cells with $\mathrm{H}_{2} \mathrm{O}_{2}$ can upregulate the expression of genes involved in antioxidative defense $[47,48]$. Our study showed that the P. yezoensis antioxidant genes PyAPX and PyMnSOD are overexpressed when exposed to $\mathrm{H}_{2} \mathrm{O}_{2}$, salinity, and UVB stress.

Other stress studies have shown that the activities of antioxidant enzymes are significantly increased in response to $\mathrm{H}_{2} \mathrm{O}_{2}$, superoxide anions, and carbonyl content under desiccation stress condition in Porphyra columbina [22]. We suggest that overexpression of these antioxidant genes occurs in response to various stresses, and this presumably is a defense mechanism that effectively reduces the intracellular ROS levels.

Chlamydomonas is a suitable model system to study the abiotic stress responses following transformation [38]. For Pyropia sp., previous studies have been conducted to identify and characterize genes using Chlamydomonas [34, 35, 39, 50]. Among these, it has been shown that transformation of Chlamydomonas with the HSP chaperone protein increased both resistance and survival rates under a variety of abiotic stress conditions.

The APX and MnSOD genes are important key components that contribute to cell homeostasis under a variety of stress conditions. Our results confirm that Chlamydomonas cells transformed with PyAPX and PyMnSOD genes had higher resistance than normal cells to abiotic stresses. It is thought that these genes are heterogeneously expressed in the Chlamydomonas cells and act as an additional stress defense 
factor.

Our study has shown the response of $P$. yezoensis antioxidant genes under abiotic stress conditions and their biological functions following their transformation into Chlamydomonas. We conclude that the overexpression of the $P y A P X$ and PyMnSOD genes that occurs following abiotic stress is an important defense mechanism in $P$. yezoensis. Furthermore, the introduction of genes encoding PyAPX and $P y M n S O D$ into Chlamydomonas may play a role in the constitutive expression in cells and supporting essential resistance factors for abiotic stresses. We have demonstrated that the $P y A P X$ and $P y M n S O D$ genes are closely related to stress tolerance and suggest that the transformation system can be used to identify various physiological and molecular functions of Pyropia.

\section{Acknowledgments}

This research was supported by the Golden Seed Project, Ministry of Oceans and Fisheries (213008-05-2-SB910), and by the National Research Foundation of Korea (NRF) grant funded by the Korea government (MSIP) (NRF2018R1D1A1B07049359).

\section{Conflict of Interest}

The authors have no financial conflicts of interest to declare.

\section{References}

1. Yoon HS, Hackett JD, Ciniglia C, Pinto G, Bhattacharya D. 2004. A molecular timeline for the origin of photosynthetic eukaryotes. Mol. Biol. Evol. 21: 809-818.

2. Hwang MS, Chung IK, Oh YS. 1997. Temperature responses of Porphyra tenera Kjellman and P. yezoensis Ueda (Bangiales, Rhodophyta) from Korea. Algae 12: 207-213.

3. Wang JX, Milton S, Hu Q. 2011. Cloning and expression of isoenzymes of superoxide dismutase in Haematococcus pluvialis (Chlorophyceae) under oxidative stress. J. Appl. Phycol. 23: 995-1003.

4. Asada K. 1999. The water-water cycle as alternative photon and electron sinks. Philos. Trans. R. Soc. Lond. B Biol. Sci. 355: 1419-1431.

5. Kwon SJ, Choi EY, Choi YJ. 2006. Proteomics studies of posttranslational modifications in plants. J. Exp. Bot. 57: 1547-1551.

6. Mur LAJ, Tim L, Carver W. 2006. No way to live: the various roles of nitric oxide in plant-pathogen interactions. J. Exp. Bot. 57: 489-505.
7. Allen R. 1995. Dissection of oxidative stress tolerance using transgenic plants. Plant Physiol. 107: 1049-1054.

8. Shigeoka S, Ishikawa T, Tamoi M, Miyagawa Y, Takeda T, Yabuta Y, et al. 2002. Regulation and function of ascorbate peroxidase isoenzymes. J. Exp. Bot. 53: 1035-1319.

9. Priya B, Premanandh J, Dhanalakshmi TR, Uma L, Prabaharan D, Subramanian G. 2007. Comparative analysis of cyanobacterial superoxide dismutases to discriminate canonical forms. BMC Genomics 8: 435-444.

10. Wang F, Wu QH, Zhang ZD, Chen SF, Zhou RC. 2013. Cloning, expression, and characterization of iron superoxide dismutase in Sonneratia alba, a highly salt tolerant mangrove tree. Protein 32: 259-265.

11. Allen R. 1995. Dissection of oxidative stress tolerance using transgenic plants. Plant Physiol. 107: 1049-1054.

12. Hernandez J, Jimenez A, Mullineaux P, Sevilla F. 2000. Tolerance of pea (Pisum sativum L.) to long-term salt stress is associated with induction of antioxidant defenses. Plant Cell Environ. 23: 853-862.

13. Sairam RK, Saxena DC. 2000. Oxidative stress and antioxidants in wheat genotypes: possible mechanism of water stress tolerance. J. Agron. Crop Sci. 184: 55-61.

14. Peltzer D, Polle A. 2001. Diurnal fluctuations of antioxidative systems in leaves of field-grown beech trees (Fagus sylvatica): responses to light and temperature. Physiol. Plant. 111: 158-164.

15. Collen J, Davison I. 1999. Stress tolerance and reactive oxygen metabolism in the intertidal red seaweeds Mastocarpus stellatus and Chondrus crispus. Plant Cell Environ. 22: 1143-1151.

16. Burritt DJ, Larkindale J, Hurd CL. 2002. Antioxidant metabolism in the intertidal seaweed Stictosiphonia arbuscula following desiccation. Planta 215: 829-838.

17. Malanga G, Puntarulo S. 1995. Oxidative stress and antioxidant content in Chlorella vulgaris after exposure to ultraviolet-B radiation. Physiol. Plant. 94: 672-679.

18. Collen J, Davison I. 1999. Reactive oxygen metabolism in intertidal Fucus spp. (Phaeophyceae). J. Phycol. 35: 62-69.

19. Collen J, Davison I. 1999. Reactive oxygen production and damage in intertidal Fucus spp. (Phaeophyceae). J. Phycol. 35: $54-61$.

20. Choo KS, Nilsson J, Pedersen M, Snoeijs P. 2005. Photosynthesis, carbon uptake and antioxidant defence in two coexisting filamentous green algae under different stress conditions. Mar. Ecol. Prog. Ser. 292: 127-138.

21. Dring MJ. 2006. Stress resistance and disease in seaweeds: the role of reactive oxygen metabolism. Adv. Bot. Res. 43: 175-207.

22. Contreras-Porcia L, Thomas D, Flores V, Correa JA. 2011. Tolerance to oxidative stress induced by desiccation in Porphyra columbina (Bangiales, Rhodophyta). J. Exp. Bot. 62: 1815-1829.

23. Pise NM, Gaikwad DK, Jagtap TG. 2013. Oxidative stress and antioxidant indices of the marine red alga Porphyra vietnamensis. Acta Bot. Croat. 72: 197-209. 
24. Wu H. 2016. Effect of different light qualities on growth, pigment content, chlorophyll fluorescence, and antioxidant enzyme activity in the red alga Pyropia haitanensis (Bangiales, Rhodophyta). Biomed. Res. Int. 2016: 7383918.

25. Den RM, Han M, Niyogi KK. 2001. Functional genomics of plant photosynthesis in the fast lane using Chlamydomonas reinhardtii. Trends Plant Sci. 6: 364-371.

26. Harris EH. 2001. Chlamydomonas as a model organism. Annu. Rev. Plant Physiol. Plant Mol. Biol. 52: 363-406.

27. Siripornadulsil S, Traina S, Verma DPS, Sayre RT. 2002. Molecular mechanisms of proline-mediated tolerance to toxic heavy metals in transgenic microalgae. Plant Cell 14: 2837-2847.

28. Schroda M, Beck CF, Vallon O. 2002. Sequence elements within an HSP70 promoter counteract transcriptional transgene silencing in Chlamydomonas. Plant J. 31: 445-455.

29. Shrager J, Hauser C, Chang CW, Harris EH, Davies J, McDermott J, et al. 2003. Chlamydomonas reinhardtii genome project. A guide to the generation and use of the cDNA information. Plant Physiol. 131: 401-408.

30. Kumar SV, Basu B, Rajam MV. 2005. Modulation of polyamine levels influence growth and cell division in Chlamydomonas reinhardtii. Physiol. Mol. Biol. Plants 11: 1-6.

31. Hippler M, Redding K, Rochaix JD. 1998. Chlamydomonas genetics, a tool for the study of bioenergetic pathways. Biochim. Biophys. Acta 1367: 1-62.

32. Remacle C, Cardol P, Coosemans N, Gaisne M, Bonnefoy N. 2006. High-efficiency biolistic transformation of Chlamydomonas mitochondria can be used to insert mutations in complex I genes. Proc. Natl. Acad. Sci. USA 103: 4771-4776.

33. Merchant SS, Prochnik SE, Vallon O, Harris EH, Karpowicz SJ, Witman GB, et al. 2007. The Chlamydomonas genome reveals the evolution of key animal and plant functions. Science 318: 245-251.

34. Kim EC, Park HS, Jung Y, Choi DW. 2011. Identification of the high-temperature response genes from Porphyra seriata (Rhodophyta) expression sequence tags and enhancement of heat tolerance of Chlamydomonas (Chlorophyta) by expression of the Porphyra HTR2 gene. J. Phycol. 47: 821-828.

35. Park HS, Jeong WJ, Kim EC, Jung Y, Lim JM, Hwang MS, et al. 2012. Heat shock protein gene family of the Porphyra seriata and enhancement of heat stress tolerance by PsHSP70 in Chlamydomonas. Mar. Biotechnol. (NY) 14: 332-342.

36. Jin YJ, Yang SW, Im SO, Jeong WJ, Park EJ, Choi DW. 2017. Overexpression of the small heat shock protein, PtsHSP19.3 from marine red algae, Pyropia tenera (Bangials, Rhodophyta) enhances abiotic stress tolerance in Chlamydomonas. J. Plant Biotechnol. 44: 287-295.

37. Lee HN, Kim SH, Han YJ, Im SO, Jeong WJ, Park EJ, et al.
2017. PsCYP1 of marine red alga Pyropia seriata (Bangiales, Rhodophyta) confers salt and heat tolerance in Chlamydomonas. J. Appl. Phycol. 29: 617-625.

38. Hema R, Senthil-Kumar M, Shivakumar S, Chandrasekhara Reddy P, Udayakumar M. 2007. Chlamydomonas reinhardtii, a model system for functional validation of abiotic stress responsive genes. Planta 226: 655-670.

39. Davison IR, Pearson GA. 1996. Enviromental stress in intertidal seaweeds. J. Phycol. 32: 197-211.

40. Flores-Moya A, Hanelt D, Figueroa FL, Altamirano M, Viñegla B, Salles S. 1999. Involvement of solar UV-B radiation in recovery of inhibited photosynthesis in the brown alga Dictyota dichotoma (Hudson) Lamouroux. J. Photochem. Photobiol. B. Biol. 49: 129-135.

41. Mittler R. 2002. Oxidative stress, antioxidants and stress tolerance. Trends Plant Sci. 7: 405-410.

42. Häder DP, Helbling EW, Williamson CE, Worrest RC. 2011. Effects of UV radiation on aquatic ecosystems and interactions with climate change. Photochem. Photobiol. Sci. 10: 242-260.

43. Dunlap WC, Shick JM, Yamamoto Y. 1999. Sunscreens, oxidative stress and antioxidant functions in marine organisms of the Great Barrier Reef. Redox Rep. 4: 301-306.

44. Li L, Zhao J, Tang X. 2009. Ultraviolet irradiation induced oxidative stress and response of antioxidant system in an intertidal macroalgae Corallina officinalis L. J. Environ. Sci. 22: 716-722.

45. Sáez CA, Roncarati F, Moenne A, Moody AJ, Brown MT. 2015. Copper-induced intra-specific oxidative damage and antioxidant responses in strains of the brown alga Ectocarpus siliculosus with different pollution histories. Aquat. Toxicol. 159: 81-89.

46. Sung MS, Hsu YT, Hsu YT, Wu TM, Lee TM. 2009. Hypersalinity and hydrogen peroxide upregulation of gene expression of antioxidant enzymes in Ulva fasciata against oxidative stress. Mar. Biotechnol. (NY) 11: 199-209.

47. Morita S, Kaminaka H, Masumura T, Tanaka K. 1999. Induction of rice cytosolic ascorbate peroxide mRNA by oxidative stress: the involvement of hydrogen peroxide in oxidative stress signaling. Plant Cell Physiol. 40: 417-422.

48. Mullineaux P, Ball L, Escobar C, Karpinska B, Creissen G, Karpinski S. 2000. Are diverse signaling pathways integrated in the regulation of Arabidopsis antioxidant defence gene expression in response to excess excitation energy? Phil. Trans. R. Soc. Lond. B Biol. Sci. 355: 1531-1540.

49. Lim JM, Ahn JW, Hwangbo K, Choi DW, Park EJ, Hwang MS, et al. 2013. Development of cyan fluorescent protein (CFP) reporter system in green alga Chlamydomonas reinhardtii and macroalgae Pyropia sp. Plant Biotechnol. Rep. 7: 407-414. 